\title{
05.3
}

\section{Фазовые переходы в смеси молекулярных кристаллов три- и пентакозана}

\author{
(C) В.А. Марихин, В.М. Егоров
}

Физико-технический институт им. А.Ф. Иоффе РАН, Санкт-Петербург, Россия

E-mail: v.marikhin@mail.ioffe.ru

Поступило в Редакцию 7 мая 2018 г.

Методом дифференциальной сканирующей калориметрии исследованы фазовые переходы $(Ф П)$ в смеси нормальных алканов: трикозана $\left(\mathrm{C}_{23} \mathrm{H}_{48}\right)$ и пентакозана $\left(\mathrm{C}_{25} \mathrm{H}_{52}\right)$. Устранение методических погрешностей позволило получить истинные значения термодинамических параметров ФП и выявить их природу. Проведен сравнительный анализ скачков теплоемкости на основе теории размытых ФП первого рода.

DOI: 10.21883/PJTF.2018.17.46573.17375

Длинноцепочечные н-алканы являются материалами с изменяющейся фазой (phase change materials), перспективными для решения вопросов поглощения, хранения и преобразования потоков тепловой энергии за счет собственных тепловых эффектов при фазовых переходах (ФП) в циклах нагревание/охлаждение. При этом н-алканы могут обеспечить решение указанных вопросов в температурной области от -40 до $80^{\circ} \mathrm{C}$, крайне важной для создания комфортных условий жизнедеятельности людей в экстремальных условиях.

В работе для выяснения температурных интервалов и эффективности теплопреобразования при ФП исследовались наиболее доступные н-алканы: трикозан $\left(\mathrm{C}_{23} \mathrm{H}_{48}\right)$ и пентакозан $\left(\mathrm{C}_{25} \mathrm{H}_{52}\right)$, приобретенные в фирме „Sigma“, а также их молекулярный сплав с соотношением компонентов 3:7. Данное соотношение было выбрано на основании литературных данных, из которых следовало, что при таком соотношении сплав должен находиться в эвтектическом состоянии. Образцы сплава помещались в алюминиевые капсулы и нагревались до температуры $363 \mathrm{~K}$ (что выше температуры плавления компонентов на несколько десятков градусов), при которой выдерживались $\sim 30 \mathrm{~min}$. Для 


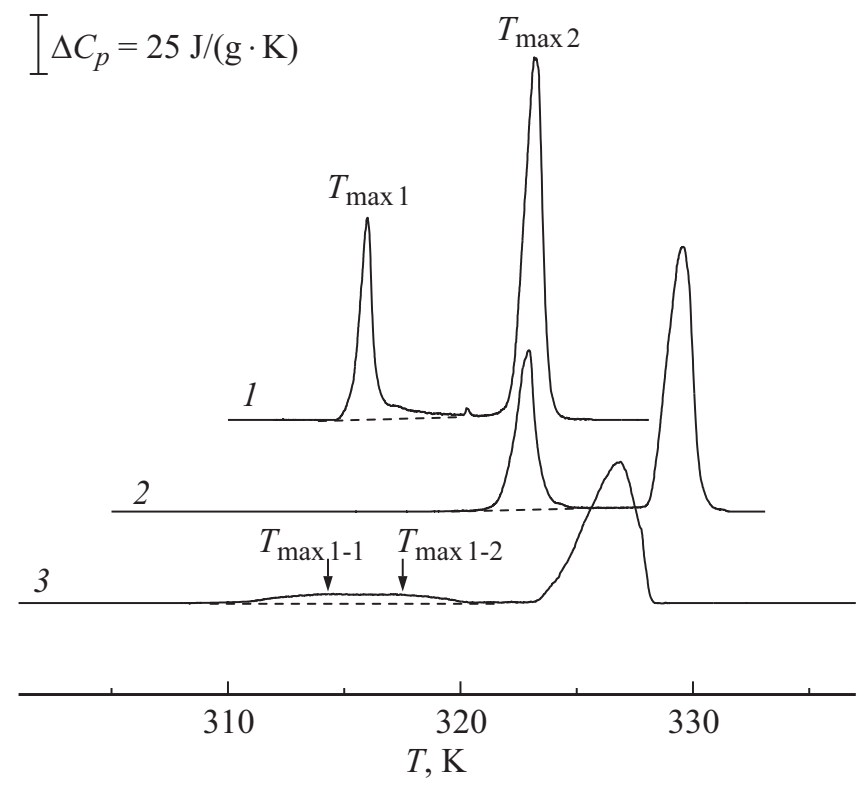

Рис. 1. Кривые ДСК, полученные при нагревании образцов три- $(1)$, пентакозана (2) и их смеси (3). Скорость сканирования $V=0.6 \mathrm{~K} / \mathrm{min}$.

уменьшения вероятности расслоения расплава на исходные компоненты в процессе кристаллизации при охлаждении (фракционирование по молекулярным массам) проводилось быстрое охлаждение расплава закалка в воду комнатной температуры.

Образцы закаленного сплава исследовались методом дифференциальной сканирующей калориметрии (ДСК), широко используемым для изучения молекулярных кристаллов различного типа, в том числе парафинов [1-3]. Тепловые свойства изучались на калориметре DSC-2 „Perkin-Elmer“ при изменении скоростей нагревания в диапазоне $0.6-5 \mathrm{~K} / \mathrm{min}$.

На рис. 1 представлены кривые ДСК, полученные при нагревании образцов трикозана (1), пентакозана (2) и их сплава (3). Как видно из рисунка, при нагревании переход из кристаллического состояния в расплав для этих парафинов и их смеси осуществляется в два 


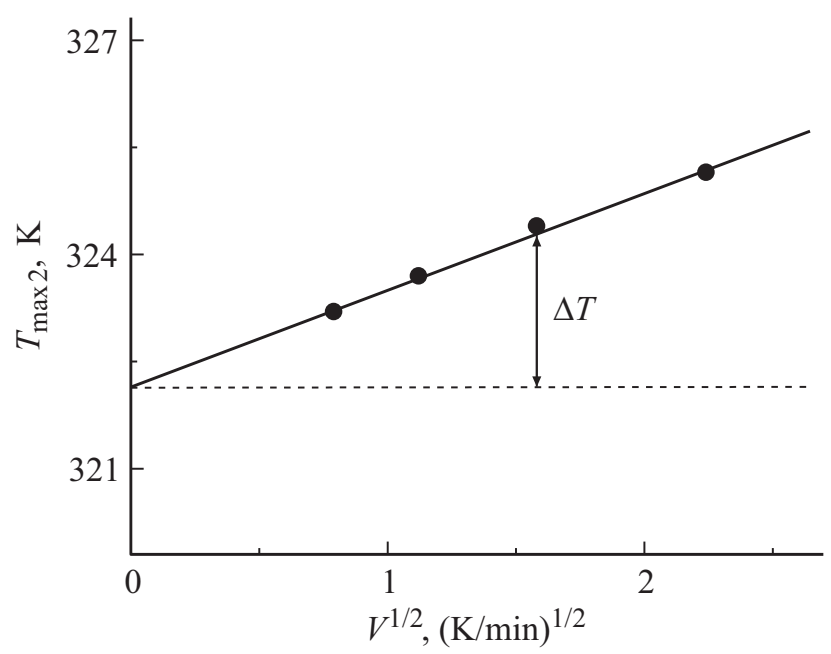

Рис. 2. Определение величины методической погрешности $\Delta T$ по зависимости $T_{\max }=f\left(V^{1 / 2}\right)$ для трикозана.

этапа (на кривых ДСК виден дублет с температурами максимумов $T_{\max 1}$ и $T_{\max 2}$. Такая картина в общем виде соответствует результатам опубликованных работ: эндотермический пик с $T_{\max 1}$ при нагревании связан с фазовым переходом в твердом состоянии, за которым следует плавление образца при температуре $T_{\max 2}$. В температурном интервале, соответствующем пику теплоемкости с $T_{\max 1}$, происходит изменение симметрии молекулярных кристаллов: орторомбическая элементарная ячейка превращается в структуру, взаимная упаковка молекул в которой близка к гексагональной (так называемая ротационная фаза, „rotor phase“ $)$. При температурах выше $T_{\max 1}$, вплоть до температуры плавления $T_{\max 2}$, эта гексагональная упаковка молекул сохраняется, что свидетельствует о сохранении дальнего порядка. Такое строение структуры можно охарактеризовать как жидкокристаллическое типа смектик.

В работе [4] показано, что при использовании метода ДСК возникает методическая погрешность (смещение пиков по температуре на величину $\Delta T$ ), обусловленная наличием термосопротивления $R$ испытываемого образца в калориметрической ячейке. Величина погрешности

Письма в ЖТФ, 2018, том 44, вып. 17 
Термодинамические параметры фазовых переходов в трикозане, пентакозане и их смеси

\begin{tabular}{l|c|c|c|c|c|c}
\hline \multicolumn{1}{c|}{ Образец } & $\begin{array}{c}\Delta H_{1}, \\
\mathrm{~J} / \mathrm{g}\end{array}$ & $\begin{array}{c}\Delta S_{1}, \\
\mathrm{~J} /(\mathrm{g} \cdot \mathrm{K})\end{array}$ & $\begin{array}{c}\Delta H_{2}, \\
\mathrm{~J} / \mathrm{g}\end{array}$ & $\begin{array}{c}\Delta S_{2}, \\
\mathrm{~J} /(\mathrm{g} \cdot \mathrm{K})\end{array}$ & $\begin{array}{c}\Delta H_{\text {summ }}, \\
\mathrm{J} / \mathrm{g}\end{array}$ & $\begin{array}{c}\Delta S_{\text {summ }}, \\
\mathrm{J} /(\mathrm{g} \cdot \mathrm{K})\end{array}$ \\
\hline Трикозан & 61 & 0.193 & 172 & 0.534 & 233 & 0.727 \\
Пентакозан & 79 & 0.245 & 155 & 0.472 & 234 & 0.717 \\
Смесь & 27 & 0.089 & 160 & 0.489 & 188 & 0.578
\end{tabular}

зависит от массы образца $m$ и скорости сканирования $V$ в соответствии с соотношением $\Delta T=R(m V)^{1 / 2}$. Однако в большинстве опубликованных работ, как правило, не устраняют эту методическую погрешность, что приводит к существенным искажениям значений термодинамических характеристик ФП. Этот недостаток может быть устранен следующим образом: по экспериментальным данным, полученным при вариации скоростей нагревания $V$, строится зависимость $T_{\max , \min }=f\left(V^{1 / 2}\right)$, которая при отсутствии структурных трансформаций должна быть линейной. Экстраполяция линейной зависимости к $V \rightarrow 0$ позволяет получить истинные, методически неискаженные значения температур переходов и определить методическую погрешность $\Delta T$. В настоящей работе сначала была получена зависимость $T_{\max }=f\left(V^{1 / 2}\right)$ для одного из исследуемых образцов определенного веса. В дальнейшем это позволило избежать трудоемких испытаний с разными скоростями нагрева для определения истинных значений $T_{\max }$ пиков на кривых ДСК. На рис. 2 представлена эта зависимость для образцов трикозана массой $5 \mathrm{mg}$. Из рисунка видно, что величина $\Delta T$ для образцов массой $5 \mathrm{mg}$ может быть определена для любой скорости нагревания; в частности, для $V=0.6 \mathrm{~K} / \mathrm{min}$ она составила $1.1 \mathrm{~K}$.

Отметим, что в отличие от температурных экспериментальные данные по энтальпии $(\Delta H)$ и энтропии $(\Delta S)$ в методе ДСК не зависят от скорости сканирования по температуре и определяются по соотношениям $\Delta H_{\exp }=\int C_{p}(T) d T$ и $\Delta S_{\exp }=\int C_{p}(T) d(\ln T)$. Суммарные значения энтальпии $\left(\Delta H_{\text {summ }}\right)$ и энтропии $\left(\Delta S_{\text {summ }}\right)$ и их составляющие для переходов первого рода $\left(\Delta H_{1}, \Delta S_{1}\right)$ и второго рода $\left(\Delta H_{2}, \Delta S_{2}\right)$ для исследованных образцов представлены в таблице.

Письма в ЖТФ, 2018, том 44, вып. 17 
Как видно из рис. 1 , эндопики $C_{p}$ для исследуемых образцов, соответствующие ФП первого и второго рода, четко разнесены на температурной шкале. Это обстоятельство позволяет выделить эндотермические пики, отвечающие структурным ФП первого рода. Анализ пиков для трикозана и пентакозана проведен ранее [2] в рамках термодинамической теории самосогласованного поля применительно к $\Lambda$-образным размытым ФП первого рода [5]. По форме пиков $C_{p}$, соответствующих переходам первого рода, были определены размеры устойчивых зародышей новой фазы - элементарные объемы перехода $\omega$. Физический смысл этих элементарных объемов состоит в следующем: при фазовом переходе внутри старой фазы происходит локализация многочисленных флуктуаций в ограниченном объеме в виде стабильных зародышей новой фазы. В дальнейшем по мере развития перехода движение межфазной границы осуществляется путем последовательных добавлений зародышей с объемом $\omega$ на возникшую межфазную границу. Оценка числа молекул, участвующих в образовании зародыша новой фазы в трикозане и пентакозане, показала, что в элементарных объемах превращения $\left(\omega \sim 100-130 \mathrm{~nm}^{3}\right)$ содержится $\sim 200-250$ молекул, т.е. область превращения захватывает весьма большой домен. Габитус (форму) этого домена можно представить в виде параллелепипеда, состоящего из параллельно упакованных „стержней“, в основании которых содержится 200-250 метиленовых цепей [6].

Из рис. 3 видно, что форма пика для смеси оказалась несимметричной, что может быть обусловлено наличием по крайней мере двух составляющих. Разделение на два пика симметричной $\Lambda$-образной формы проводилось при условии равенства энтальпии экспериментально полученного пика сумме энтальпий двух симметричных пиков. При вариации параметров, используемых для расчета $\omega$ для каждого из симметричных пиков, наилучшее совпадение расчетных и экспериментальных зависимостей наблюдалось при значениях $\omega=96 \mathrm{~nm}^{3}$ для низкотемпературного пика с максимумом теплоемкости при $T_{\max 1-1}=313.8 \mathrm{~K}$ и $\omega=110 \mathrm{~nm}^{3}$ для более высокотемпературного пика с максимумом теплоемкости при $T_{\max 1-2}=317.3 \mathrm{~K}$. На рис. 3 зависимости $\Delta C_{p}(T)$, полученные в результате расчета $\Lambda$-образных пиков, показаны штриховыми линиями.

Природа этих $\Lambda$-образных пиков связана, по-видимому, с ФП в отдельных фракциях трикозана и пентакозана, частично выделившихся вследствие расслоения и закристаллизовавшихся из расплава при

Письма в ЖТФ, 2018, том 44, вып. 17 


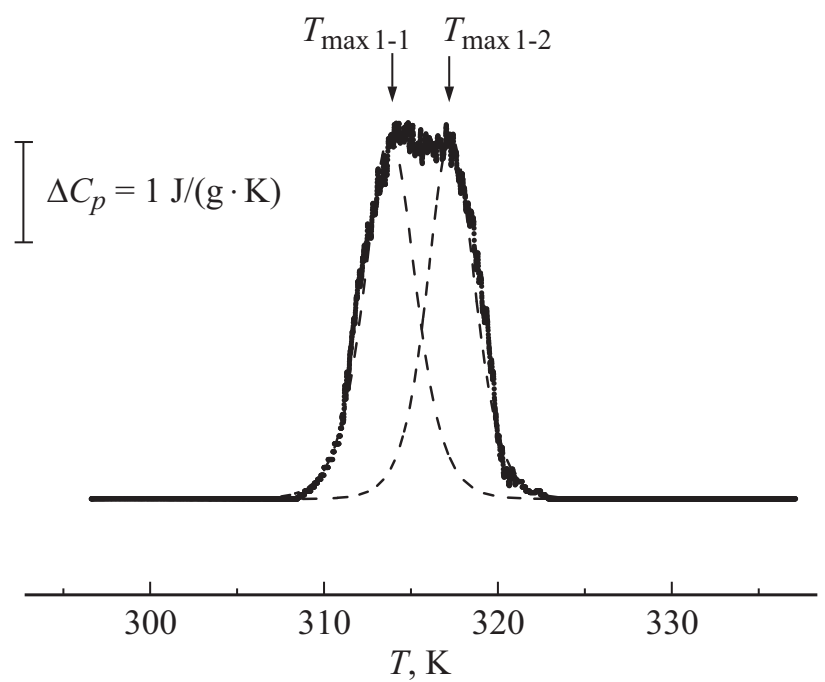

Рис. 3. Эндотермический пик, отвечающий твердофазному переходу в смеси три- и пентакозана. Жирная линия - экспериментальные данные, тонкие штриховые линии - результат расчета.

охлаждении. По значению $\Delta H_{1}$ смеси (см. таблицу) можно определить величину избыточной энтальпии незакристаллизовавшейся части смеси. Для этого необходимо из величины $\Delta H_{1}=73 \mathrm{~J} / \mathrm{g}$ твердофазного перехода исходных парафинов в соотношении $3: 7$ вычесть $\Delta H_{1}$ смеси. Эта разница составляет $\Delta H_{e x c}=46 \mathrm{~J} / \mathrm{g}$, или $63 \%$ от величины $\Delta H_{1}$ исходных компонентов. В том случае, если эта доля избыточной энергии пропорциональна объемной доле смеси парафинов, находящихся в жидкокристаллическом состоянии, можно предположить, что надмолекулярная структура смеси имеет весьма необычное строение: кристаллические образования в виде ламелей из молекул $\mathrm{C}_{23} \mathrm{H}_{48}$ и $\mathrm{C}_{25} \mathrm{H}_{52}$, составляющие $37 \%$ объема, окружены жидкокристаллической фазой из смеси параллельно упакованных „стержней“, т.е. молекул трикозана $\mathrm{C}_{23} \mathrm{H}_{48}$ и пентакозана $\mathrm{C}_{25} \mathrm{H}_{52}$. Поскольку эти „стержни“ имеют разную длину, жидкокристаллическую фазу можно определить как нематическую.

Письма в ЖТФ, 2018, том 44, вып. 17 
Работа выполнена при финансовой поддержке Программы Президиума РАН № 32 „Наноструктуры: физика, химия, биология, основы технологий“ и Российского фонда фундаментальных исследований (код проекта 16-03-00493А).

\section{Список литературы}

[1] Qi W.H. // Acc. Chem. Res. 2016. V. 49. N 9. P. 1587-1595.

[2] Егоров В.М., Марихин В.А. // ФТТ. 2016. Т. 58. В. 12. С. 2482-2487.

[3] Ukrainczyk N., Kurajica S., Šipušice J. // Chem. Biochem. Eng. Q. 2010. V. 24. N 2. P. $129-137$.

[4] Illers K.-H. // Eur. Polym. J. 1974. V. 10. N 10. P. 911-916.

[5] Малыгин Г.А. // УФН. 2001. Т. 171. № 2. С. 187-212.

[6] Егоров В.М., Марихин В.А. // ФТТ. 2016. Т. 58. В. 11. С. 2269-2273.

Письма в ЖТФ, 2018, том 44, вып. 17 